\title{
High capacity multicomponent hydrogen storage materials: Investigation of the effect of stoichiometry and decomposition conditions on the cycling behaviour of $\mathrm{LiBH}_{4}-\mathrm{MgH}_{2}$
}

\author{
Gavin S. Walker ${ }^{\mathrm{a}, *}$, David M. Grant ${ }^{\mathrm{a}}$, Tobias C. Price ${ }^{\mathrm{a}}$, Xuebin Yu ${ }^{\mathrm{a}, \mathrm{b}}$, Vincent Legrand ${ }^{\mathrm{c}}$ \\ a Division of Fuels and Power Technology, Faculty of Engineering, University of Nottingham, University Park, Nottingham NG7 2RD, United Kingdom \\ ${ }^{\mathrm{b}}$ Department of Materials Science, Fudan University, Shanghai 200433, China \\ ' Institut Laue Langevin, 6 rue Jules Horowitz, BP 156, 38042 Grenoble Cedex 9, France
}

$\mathrm{LiBH}_{4}-\mathrm{MgH}_{2}$ is an attractive reversible hydrogen storage system, it combines two high capacity hydrides (18.3 and $7.6 \mathrm{wt} . \%$, respectively) and the concerted dehydrogenation reaction has a smaller enthalpy change than either species on its own. The latter effect leads to a destabilisation of the hydrided products and results in a lowering of the dehydrogenation temperature. In situ neutron diffraction experiments have been undertaken to characterise the mechanism of decomposition of the $\mathrm{LiBD}_{4}-\mathrm{MgD}_{2}$ system, with an emphasis on investigating the synergistic effects of the components during cycling under various conditions. This study compares the effect of stoichiometry of the multicomponent system on the cycling mechanism. Results show that $\mathrm{LiBD}_{4}-\mathrm{MgD}_{2}$ in a 2:1 molar ratio can be reversibly dehydrogenated under low pressures of hydrogen or under vacuum, contrary to earlier reports in the literature, although the reaction was only partially reversed for the $2: 1$ mixture decomposed under vacuum. This work shows that the reaction pathway was affected by dehydrogenation conditions, but the stoichiometry of the multicomponent system played a minor role.

\author{
Keywords: \\ Hydrogen \\ Storage \\ Complex hydrides \\ Reaction mechanism
}

\section{Introduction}

The compact storage of hydrogen is a key challenge for the utilisation of hydrogen in transport and portable electronics applications. Metal hydrides have high volumetric capacities but classic hydridable alloys such as $\mathrm{LaNi}_{5}$ have very low gravimetric capacities (e.g. $0.11 \mathrm{~kg}\left(\mathrm{H}_{2}\right) \mathrm{L}^{-1}$, but only $1.4 \mathrm{wt}$.\%). Higher capacity metal hydrides and complex hydrides often require higher temperatures to release the hydrogen, e.g. $\mathrm{LiBH}_{4}$ which has volumetric and gravimetric storage capacities of $0.12 \mathrm{~kg}\left(\mathrm{H}_{2}\right) \mathrm{L}^{-1}$ and $18.5 \mathrm{wt} . \%$, respectively, but requires temperatures in excess of $500^{\circ} \mathrm{C}$ to fully dehydrogenate the material.

Destabilisation is a strategy pioneered by Reilly and Wiswall in the 1960s, the basic concept was to use alloys to make the hydrides less thermodynamically stable [1]. A classic example is $\mathrm{Mg}_{2} \mathrm{Ni}$ which can be hydrogenated to form $\mathrm{Mg}_{2} \mathrm{NiH}_{4}$, but although there is a modest reduction in the thermodynamic stability (the temperature at which 1 bar of hydrogen is evolved, $T(1$ bar $)$, is $255^{\circ} \mathrm{C}$ ), there is also a significant loss in hydrogen capacity (3.6 wt.\%). Such

\footnotetext{
* Corresponding author. Tel.: +44 1159513752; fax: +44 1159513800

E-mail address: gavin.walker@nottingham.ac.uk (G.S. Walker).
}

systems are examples of destabilisation for a single phase hydride. Multicomponent hydrogen storage systems comprise of more than one phase in the hydrogen loaded state. These can be merely physical mixtures or a composite (i.e. where one phase acts as a host matrix). Both phases react during dehydrogenation, hence one phase is not simply acting as a catalyst, and often the dehydrogenated products consist of more than one phase (although this does not have to be the case). Given the high hydrogen capacities of complex hydrides such as borohydrides, alanates and amides, it is of no surprise that many of the systems studied have a complex hydride as one of the phases, the other phase typically being a binary hydride (e.g. $\mathrm{LiBH}_{4}-\mathrm{MgH}_{2}$ ), but addition of other complex hydride phases has also been tried (e.g. $\mathrm{LiAlH}_{4}-\mathrm{LiNH}_{2}$ ).

The underlying principle to destabilisation is best illustrated using an enthalpy diagram such as that shown in Fig. 1. The example on the left would be illustrative of destabilisation of a binary hydride, $\mathrm{YH}_{2}$. Without the addition of a second phase, $\mathrm{YH}_{2}$ will decompose forming the elements with a change in enthalpy of $\Delta H_{\mathrm{a}}$ (i.e. $-\Delta H_{\mathrm{f}}\left(\mathrm{YH}_{2}\right)$, where $\Delta H_{\mathrm{f}}$ is the enthalpy of formation). Introducing a second phase, $\mathrm{Z}$, to $\mathrm{YH}_{2}$ now allows an alternative reaction to occur where $\mathrm{Y}$ can combine with $\mathrm{Z}$ to form $\mathrm{YZ}$, which has a lower change in enthalpy, $\Delta H_{\mathrm{b}}$ (i.e. $\Delta H_{\mathrm{b}}=\Delta H_{\mathrm{a}}+\Delta H_{\mathrm{f}}(\mathrm{YZ})$ ). For example, Si can be added to $\mathrm{MgH}_{2}$ to reduce the enthalpy of dehydrogenation 


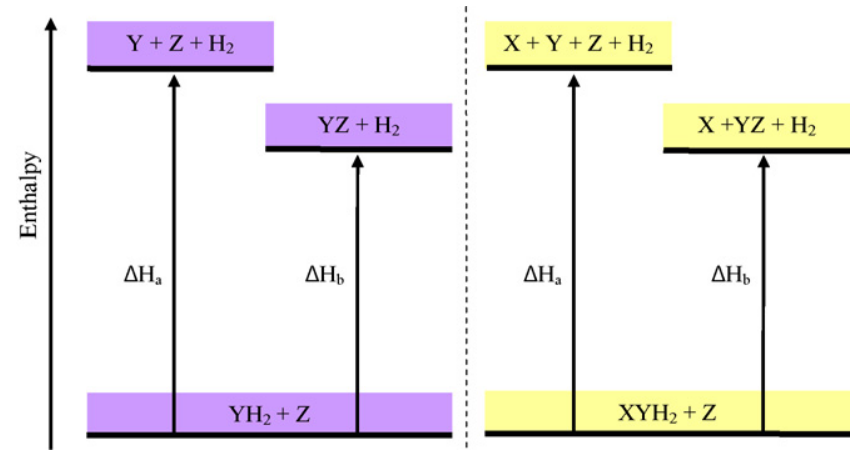

Fig. 1. Enthalpy diagram showing the smaller dehydrogenation endotherm for the destabilised multicomponent system. The destabilized dehydrogenation product is for the formation of a single phase on the left and for two product phases on the right.

from $75.3 \mathrm{~kJ} \mathrm{~mol}^{-1}\left(\mathrm{H}_{2}\right)$, for $\mathrm{MgH}_{2}$ on its own, to $36.4 \mathrm{~kJ} \mathrm{~mol}^{-1}\left(\mathrm{H}_{2}\right)$ via the following reaction [2].

$2 \mathrm{MgH}_{2}+\mathrm{Si} \rightarrow \mathrm{Mg}_{2} \mathrm{Si}+2 \mathrm{H}_{2}$

The reactions on the right in Fig. 1, give an example common for complex hydrides, where the hydrided material dehydrogenates to form two other product phases X and Y. For example, lithium tetrahydridoborate, $\mathrm{LiBH}_{4}$, dehydrogenates to form the binary hydride of lithium and the elements boron and hydrogen:

$2 \mathrm{LiBH}_{4} \rightarrow 2 \mathrm{LiH}+2 \mathrm{~B}+3 \mathrm{H}_{2}$

Note that for this example, not all the dehydrogenation products are elements, this is because lithium hydride itself is a very stable compound and requires much higher temperatures to decompose it than one normally employs $\left(>600^{\circ} \mathrm{C}\right)$. Adding a suitable second phase, $\mathrm{Z}$, to destabilise $\mathrm{XYH}_{2}$ leads to an alternative reaction where $\mathrm{Z}$ combines with one of the elements in the hydride forming YZ. For example, $\mathrm{MgH}_{2}$ can be added to $\mathrm{LiBH}_{4}$ resulting in the following reaction [3].

$$
2 \mathrm{LiBH}_{4}+\mathrm{MgH}_{2} \leftrightarrows 2 \mathrm{LiH}+\mathrm{MgB}_{2}+4 \mathrm{H}_{2}
$$

The enthalpy of dehydrogenation reduces from $58.6 \mathrm{~kJ} \mathrm{~mol}^{-1}\left(\mathrm{H}_{2}\right)$ for molten $\mathrm{LiBH}_{4}$ to $39.8 \mathrm{~kJ} \mathrm{~mol}^{-1}\left(\mathrm{H}_{2}\right)$ for the equivalent destabilised reaction [4]. For both examples the change in enthalpy for the destabilised reaction, $\Delta H_{\mathrm{b}}$, is less than that for the hydride on its own, $\Delta H_{\mathrm{a}}$ and thus the destabilised reaction will have a correspondingly lower $T(1 \mathrm{bar})$. To put it another way, at a given temperature the destabilised multicomponent hydride will have a higher plateau pressure than the hydride on its own.

It has been argued that $\Delta S$ for most metal hydrides will approximately equal the entropy of the evolved hydrogen, $c a$. $130 \mathrm{~J} \mathrm{~K}^{-1} \mathrm{~mol}^{-1}\left(\mathrm{H}_{2}\right)$ [5], but complex hydrides have a lower $\Delta S$, e.g. $95 \mathrm{~J} \mathrm{~K}^{-1} \mathrm{~mol}^{-1}\left(\mathrm{H}_{2}\right)$ as determined for $\mathrm{LiBH}_{4}$ [6]. Using these two values for $\Delta S$ one can estimate with Eq. (4) the $\Delta H$ required for $T(1 \mathrm{bar})$ to be less than $200^{\circ} \mathrm{C}$; for metal hydrides it is $61 \mathrm{~kJ} \mathrm{~mol}^{-1}\left(\mathrm{H}_{2}\right)$ and for complex hydrides it is $45 \mathrm{~kJ} \mathrm{~mol}^{-1}\left(\mathrm{H}_{2}\right)$. There are further limitations, if destabilisation results in a negative $\Delta H$ (i.e. dehydrogenation becomes exothermic) this has the effect of making the hydrided state thermodynamically unstable and would result in a non-reversible dehydrogenation reaction because hydrogenation would have a positive change in enthalpy and also a negative change in entropy (assuming no gaseous species are formed during hydrogenation) and thus $\Delta G$ would always be positive. Thinking about the practicalities of a hydrogen store, it would be undesirable to use a material that had a hydrogen equilibrium pressure of 200 bar at room temperature. Releasing the hydrogen from the store is not the problem (although heavier cylinders would be needed to cope with the pressure), but being able to provide an adequate over pressure for a sufficiently fast charging rate starts to become an issue. Perhaps more important though are safety concerns during small temperature excursions (either from a hot day or from a fire), merely increasing the temperature of the store by $25^{\circ} \mathrm{C}$ would lead to a doubling of the plateau pressure to over 400 bar. Hence, the target range of $\Delta H$ for practical systems is $26-61 \mathrm{~kJ} \mathrm{~mol}^{-1}\left(\mathrm{H}_{2}\right)$ for $\Delta S=130 \mathrm{~J} \mathrm{~K}^{-1} \mathrm{~mol}^{-1}\left(\mathrm{H}_{2}\right)$ and $15-45 \mathrm{~kJ} \mathrm{~mol}^{-1}\left(\mathrm{H}_{2}\right)$ for $\Delta S=95 \mathrm{~J} \mathrm{~K}^{-1} \mathrm{~mol}^{-1}\left(\mathrm{H}_{2}\right)$.

$T(1$ bar $)=\frac{\Delta H}{\Delta S}$

The initial paper from Vajo et al. showed that the dehydrogenation conditions affected the reaction path [3], under a hydrogen atmosphere the dehydrogenation followed reaction equation (3). However, if the dehydrogenation was done under a dynamic vacuum magnesium boride was not formed and the following reaction appeared to proceed [3].

$2 \mathrm{LiBH}_{4}+\mathrm{MgH}_{2} \rightarrow 2 \mathrm{LiH}+2 \mathrm{~B}+\mathrm{Mg}+4 \mathrm{H}_{2}$

Surprisingly, these end products could not be hydrogenated suggesting that $\mathrm{MgB}_{2}$ plays an important role in the reverse reaction. Work from our research group has investigated a magnesium-rich multicomponent system to study whether the reaction path is influenced by the stoichiometry of the solid phases [7]. This work showed that under an inert carrier gas all the hydrogen in the system could be liberated and the end products were a mixture of $\alpha$ - and $\beta$-alloys of $\mathrm{Mg}$-Li and elemental boron (reaction (6)). Even though this reaction did not yield $\mathrm{MgB}_{2}$ it was shown that the reaction could be reversed.

$$
\begin{aligned}
& 0.30 \mathrm{LiBH}_{4}+\mathrm{MgH}_{2} \leftrightarrows 0.78 \mathrm{Li}_{0.184} \mathrm{Mg}_{0.816}+0.52 \mathrm{Li}_{0.30} \mathrm{Mg}_{0.70} \\
& \quad+0.3 \mathrm{~B}+1.60 \mathrm{H}_{2}
\end{aligned}
$$

This would appear to be very different behaviour to that found for the 2:1 ratio under vacuum. Other researchers have focussed on the reaction of the $2: 1$ mixture under hydrogen [8-11], but it is important we understand properly the effect of stoichiometry of such multicomponent systems and the effect of the dehydrogenation conditions on the reaction paths and reversibility of the system. This study compares the dehydrogenation reactions for both the 0.3:1 and 2:1 ratio under both dynamic vacuum and under 1 bar of hydrogen. The dehydrogenation under a hydrogen pressure of the 0.3:1 mixture has not been investigated before and it is of interest to see whether a similar reaction to that in reaction (3) exists and whether this reaction is reversible. This work also seeks to identify whether Mg-Li alloys form for the 2:1 ratio under a dynamic vacuum, which to date has not been identified. These reactions have been probed by in situ neutron powder diffraction using the deuterium isotopes of the $\mathrm{LiBH}_{4}$ and $\mathrm{MgH}_{2}$, the samples being prepared by ball milling. The reversibility of the systems has also been studied to try and understand why the 2:1 mixture when dehydrogenated under vacuum was not reversible, unlike the 0.3:1 mixture.

\section{Experimental details}

Materials used were $\mathrm{LiBH}_{4}$ (Acros Organics, 95\%), $\mathrm{LiBD}_{4}$ (Katchem, 98\%) and $\mathrm{MgH}_{2}$ (Alfar Aesar, 98\%) which were ball milled and subsequently deuterided $\left(99.8 \%, \mathrm{D}_{2}, \mathrm{BOC}\right)$ to form $\mathrm{MgD}_{2}$ through multiple deuteriding cycles. All handling procedures were conducted under an inert atmosphere. $1.5 \mathrm{~g}$ mixtures of $\mathrm{LiBD}_{4}-\mathrm{MgD}_{2}$, with a $\mathrm{Li}$ to $\mathrm{Mg}$ molar ratio of $0.3: 1$ and $2: 1$, were transferred in sealed milling pots from the glove box to a Fritsch Rotary P5 ball mill and were mechanically milled for $1 \mathrm{~h}$ under $\mathrm{Ar}$ gas at $300 \mathrm{rpm}$. 

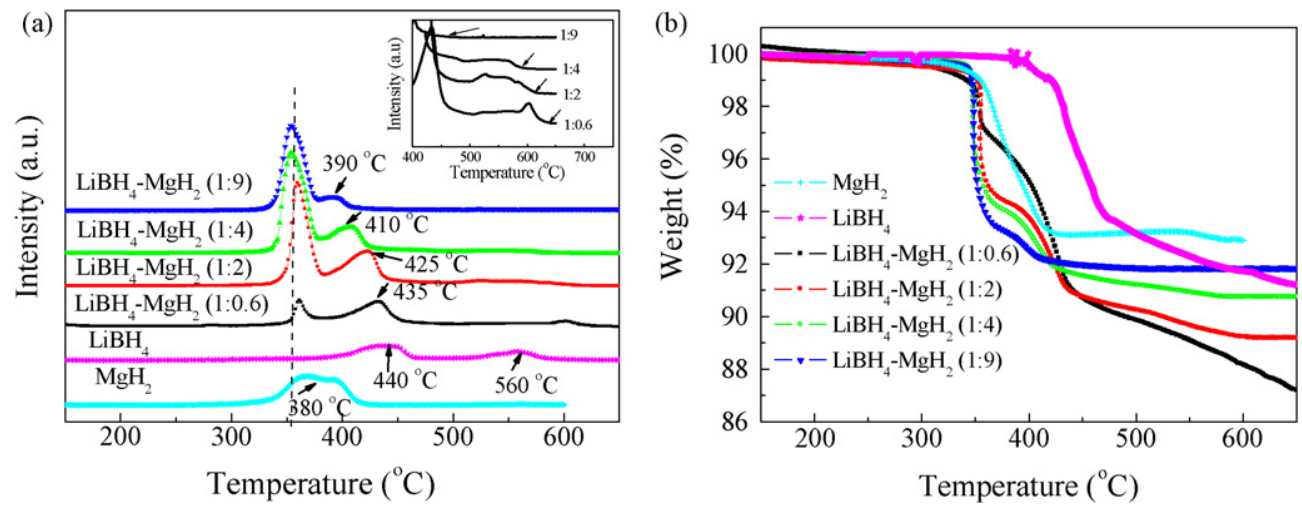

Fig. 2. Mass spectroscopy (a) and thermogravimetric analysis (b) for the evolution of $\mathrm{H}_{2}$ from $\mathrm{LiBH}_{4}-\mathrm{MgH}_{2}$ samples milled for $1 \mathrm{~h}$ (heating rate of $10{ }^{\circ} \mathrm{C}$ min ${ }^{-1}$ ).

Hydrogen release was measured by differential thermal analysis/thermogravimetry (DTA-TG, TA-STD 600) connected to a mass-spectrometer (MS, Hiden) using a heating rate of $10^{\circ} \mathrm{C} \mathrm{min}^{-1}$ under $1 \mathrm{~atm}$ argon with a purge rate $200 \mathrm{~cm}^{3} \mathrm{~min}^{-1}$. Typical sample quantities were 5-10 mg, the samples were loaded into alumina crucibles with a loose aluminium lid pressed on top. The samples were transferred to the instrument under $\mathrm{Ar}$ in a sealed sample bottle to minimise the likelihood of air/moisture contamination. Powder XRD was performed on a Bruker D8 Advance, step size was 0.02 and dwell time $0.5 \mathrm{~s}$, a copper source with wavelength $1.542 \AA$ was used. Powders were analysed on a Si single crystal wafer, covered by an amorphous polymer tape to avoid oxidation during the measurement.

Neutron diffraction, ND, measurements on powder samples were performed at the Institut Laue-Langevin (ILL Grenoble, France) using the two-axis D20 instrument in its high flux configuration $\left(\lambda=2.4 \AA\right.$, flux $\left.=10^{8} \mathrm{~ns}^{-1} \mathrm{~cm}^{-2}\right)[12]$. Data was analysed using Large Array Manipulation Program (LAMP) version 6. Samples of $1 \mathrm{~g}$ mass were loaded into stainless steel 316L vessels under an inert gas (Ar). An internal temperature calibration of a blank sample vessel was used to calibrate any variance from the in situ sample temperatures measured on the outside of the vessel during the neutron diffraction experiments. A gas manifold system including an MKS 890B Baratron allowed an initial 1 bar of deuterium to be applied to samples subsequently run under sealed conditions. Both $0.3: 1$ and 2:1 ratio samples were heated to $570{ }^{\circ} \mathrm{C}$ under the two pressure conditions; firstly sealed with an initial 1 bar deuterium and secondly under a dynamic vacuum. Deuteriding was attempted for all the decomposed materials at $400^{\circ} \mathrm{C}$, for $4 \mathrm{~h}$ under $100 \mathrm{bar}$ of $\mathrm{D}_{2}$. The samples were cooled to $250^{\circ} \mathrm{C}$ before collecting the ND data.

\section{Results}

Fig. 2 shows the MS and TGA data for ball milled $\mathrm{LiBH}_{4}$ and $\mathrm{MgH}_{2}$ and for mixtures of the two phases. It can be seen that even after ball milling, the dehydrogenation of $\mathrm{MgH}_{2}$ has poor kinetics, there appears to be two merged peaks in the MS results, with an onset of dehydrogenation at $320^{\circ} \mathrm{C}$, finishing by $410^{\circ} \mathrm{C}$, and a corresponding weight loss of $6.8 \%$. The $\mathrm{LiBH}_{4}$ onset of dehydrogenation did not start until $400^{\circ} \mathrm{C}$ with two peaks at 440 and $540^{\circ} \mathrm{C}$. The sample had not completely decomposed by the end of the experiment having a weight loss of just $9.0 \%$. The ball milled mixtures of $\mathrm{LiBH}_{4}-\mathrm{MgH}_{2}$ however, showed a much more rapid evolution at $\mathrm{ca} .350^{\circ} \mathrm{C}$, the peak temperature reducing to just below $350^{\circ} \mathrm{C}$ with increasing $\mathrm{MgH}_{2}$ content. The mixtures had a second hydrogen evolution at $435^{\circ} \mathrm{C}$ for the $1: 0.6 \mathrm{wt}$ ratio sample which again reduced to lower temperatures with increasing $\mathrm{MgH}_{2}$ content $\left(390^{\circ} \mathrm{C}\right.$ for the $1: 9$ sample). There was a further release of hydrogen at temperatures greater than $500^{\circ} \mathrm{C}$ (see Fig. 2(a) insert). The weight loss for the first event increased with increasing $\mathrm{MgH}_{2}$ content and the weight loss for the second and third events decreased.

$\mathrm{XRD}$ for the as prepared $\mathrm{MgD}_{2}$ sample showed that the majority phase was that of $\mathrm{MgD}_{2}$ with only weak diffuse reflections for $\mathrm{Mg}$ and $\mathrm{MgO}$. This deuterated material was ball milled with $\mathrm{LiBD}_{4}$ in a $2: 1$ and $0.3: 1$ molar ratio (equivalent to the $1: 0.6$ and $1: 4$ weight ratio samples shown in Fig. 2). In situ ND data was collected whilst heating the samples under an initial 1 bar $D_{2}$ pressure in a closed vessel. The results for both the 2:1 and 0.3:1 samples are given in Fig. 3 and the temperatures at which the decomposition phases formed are given in Table 1. For the 2:1 sample the initial phases of the low temperature orthorhombic phase for $\mathrm{LiBD}_{4}$ and $\mathrm{MgD}_{2}$ were clearly observed (it should be noted that in Figs. 3 and 4 there are some weak diffraction lines from the stainless steel sample vessel and that these reflections shift to higher $d$-spacings because of thermal expansion). On heating, the $\mathrm{LiBD}_{4}$ orthorhombic phase changes into the higher temperature hexagonal phase, which then melts at ca. $270{ }^{\circ} \mathrm{C}$ resulting in the loss of this diffraction pattern but the appearance of a very broad, low-intensity amorphous hump centered at $3.4 \AA$. At $335^{\circ} \mathrm{C}$, the $\mathrm{MgD}_{2}$ phase was lost and a $\mathrm{Mg}$ phase appeared, but this in turn was lost at $520^{\circ} \mathrm{C}$ and the concomitant appearance of $\mathrm{MgB}_{2}$ and $\mathrm{LiD}$ phases. It is also interesting to note that the amorphous hump from the liquid $\mathrm{LiBD}_{4}$ decreased in intensity from $440^{\circ} \mathrm{C}$. The final pressure in the vessel after decomposition was ca. 11 bar. The decomposition of the 0.3:1 sample under a starting pressure of 1 bar was similar to that for the $2: 1$. It should be noted that the initial sample temperature as shown in Fig. 3 is already above $150^{\circ} \mathrm{C}$, i.e. the $\mathrm{LiBD}_{4}$ had already transformed to the hexagonal isomorph. Another obvious difference is the greater intensity for the $\mathrm{MgD}_{2} \mathrm{ND}$ pattern. It can be seen that the phases forming during the decomposition are similar to those for the $2: 1$ sample, however, a significant difference was that the appearance of $\mathrm{LiD}$ and $\mathrm{MgB}_{2}$ phases occurred at a lower temperature of $475^{\circ} \mathrm{C}$ and although there was a decrease in the intensity of the Mg ND pattern, this phase was still present at the end of the decomposition experiment.

Table 1

Decomposition product formation temperatures as determined by ND data for the decomposition of $\mathrm{LiBD}_{4}: \mathrm{MgD}_{2}$ samples.

\begin{tabular}{lllllll}
\hline $\begin{array}{l}\text { Decomposition } \\
\text { conditions }\end{array}$ & Sample & \multicolumn{6}{c}{ Temperature of formation $\left({ }^{\circ} \mathrm{C}\right)$} \\
\cline { 3 - 7 } & & $\mathrm{Mg}$ & $\mathrm{MgB}_{2}$ & $\mathrm{LiD}$ & $\alpha$-Alloy & $\beta$-Alloy \\
\hline Under $\mathrm{D}_{2}$ & $2: 1$ & 335 & 515 & 515 & - & - \\
& $0.3: 1$ & 320 & 475 & 475 & - & - \\
Under vacuum & $2: 1$ & 330 & - & 485 & 485 & 550 \\
& $0.3: 1$ & 330 & - & 400 & 435 & 540 \\
\hline
\end{tabular}




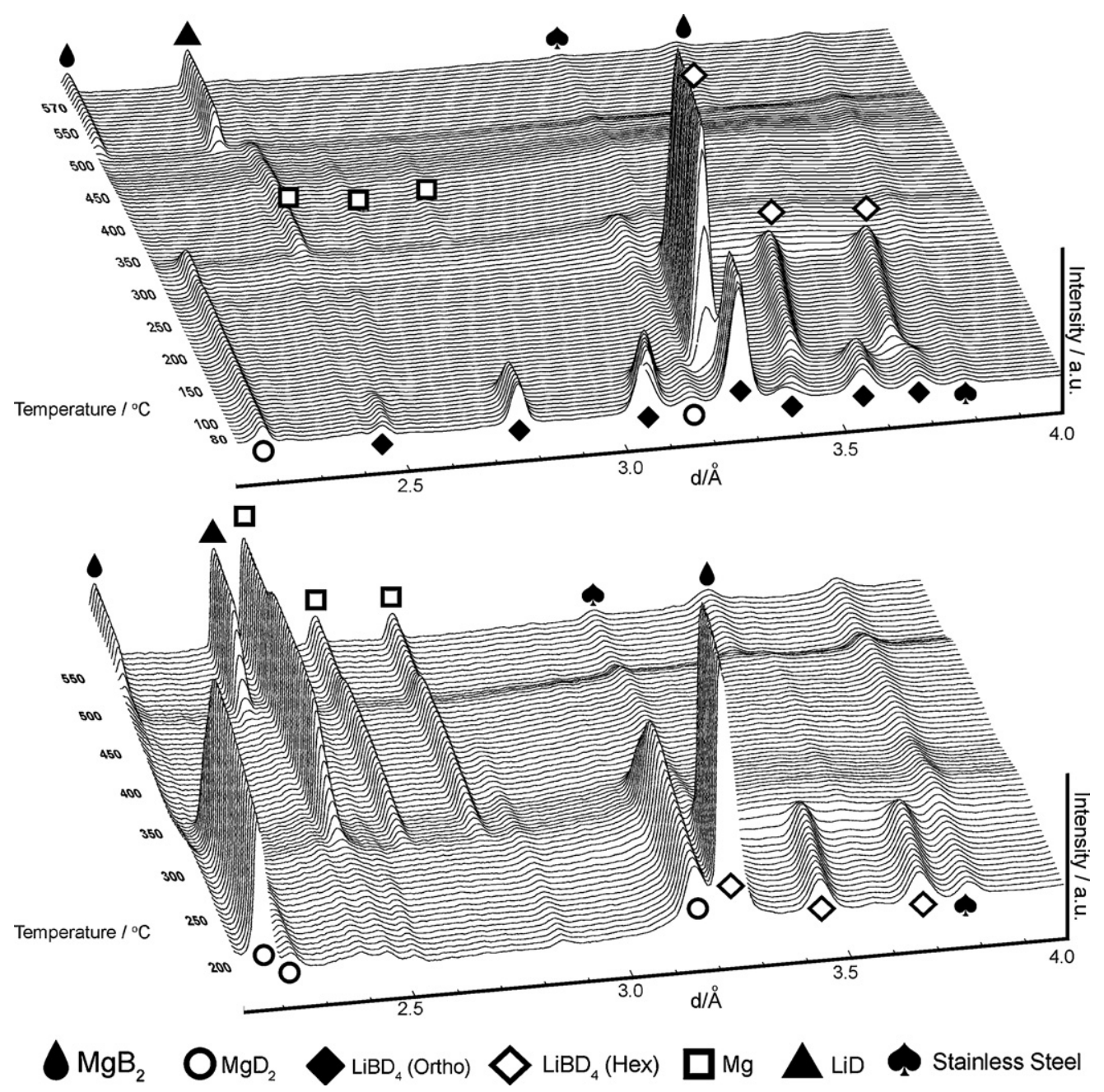

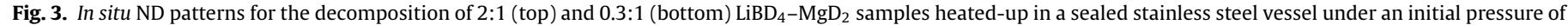
1 bar of $D_{2}$.

For the samples heated under a dynamic vacuum, a similar sequence of events occurred below $400^{\circ} \mathrm{C}$ to those for the samples under an initial 1 bar $\mathrm{D}_{2}$ atmosphere (see Fig. 4 and Table 1). For the $2: 1$ sample the amorphous hump started to diminish at $440^{\circ} \mathrm{C}$ and a LiD phase formed at $490^{\circ} \mathrm{C}$. Concomitant with the formation of LiD there was a small decrease in the $d$-spacing for the $\mathrm{Mg}$ metal pattern, e.g. from 2.601 to $2.575 \AA$, corresponding to the formation of an $\alpha-\mathrm{Li}_{x} \mathrm{Mg}_{y}$ alloy phase. This weak pattern was lost with the emergence of a reflection for the $\beta-\mathrm{Li}_{x} \mathrm{Mg}_{y}$ alloy at $550{ }^{\circ} \mathrm{C}$. The formation of the alloy phases are more easily observed in the ND data for the 0.3:1 sample (Fig. 4) The change in $d$-spacing is more clearly seen in Fig. 5, where rather than observing an increase in the $d$-spacing, as expected from thermal expansion, this image clearly shows the contraction in the lattice parameters for the magnesiumcontaining metallic phase, most notably the change in the $(002)$ reflection. In contrast to the $2: 1$ sample, this time the LiD phase disappeared completely and both the $\alpha$ - and $\beta$-alloys were present at the end of the decomposition. Another significant difference for this 0.3:1 sample in comparison with all the other decomposition reactions was that the intensity of the amorphous hump started to decrease at a lower temperature, $400^{\circ} \mathrm{C}$, and that the formation of LiD started at the same temperature. For both samples decomposed under vacuum there was no evidence of $\mathrm{MgB}_{2}$ formation by the end of the decomposition at $570^{\circ} \mathrm{C}$.

The decomposition products were redeuterided under $100 \mathrm{bar}$ $\mathrm{D}_{2}$ at $400^{\circ} \mathrm{C}$ for $4 \mathrm{~h}$. The ND patterns for the products are given in Fig. 6 and show that $\mathrm{LiBD}_{4}$ and $\mathrm{MgD}_{2}$ were reformed for all the samples. No magnesium-containing decomposition products were identified after deuteriding, but there was a LiD reflection for all the samples except the 0.3:1 sample decomposed under $D_{2}$. Given the detection limit for ND, this indicates that the formation of $\mathrm{LiBD}_{4}$ was $>95 \%$ complete. The relative intensity of the LiD reflection in comparison to those for $\mathrm{LiBD}_{4}$ and $M g D_{2}$ was used to quantify the reversibility of the other products. The lowest conversion of $\mathrm{LiD}$ to $\mathrm{LiBD}_{4}$ was found for the $2: 1$ sample decomposed under vacuum (5\%), the next was for the $2: 1$ sample decomposed under $D_{2}(40 \%)$ and then the $0.3: 1$ decomposed under $D_{2}$ (70\%).

\section{Discussion}

The TGA-MS results presented in Fig. 2 show that the $\mathrm{LiBH}_{4}-\mathrm{MgH}_{2}$ samples evolved hydrogen under an inert carrier gas in three stages. It has previously been shown that these stages correspond to the sequential decomposition of the $\mathrm{MgH}_{2}, \mathrm{LiBH}_{4}$ and $\mathrm{LiH}$ phases (the latter resulting from the decomposition of $\mathrm{LiBH}_{4}$ ) [7]. The relative proportion of hydrogen evolved during these three stages was of course dependent upon the ratio of the as prepared samples. Comparing the dehydrogenation temperatures showed a marked improvement for the $\mathrm{LiBH}_{4}-\mathrm{MgH}_{2}$ mixtures in comparison to the individual $\mathrm{LiBH}_{4}$ and $\mathrm{MgH}_{2}$ samples. There was also a marked 

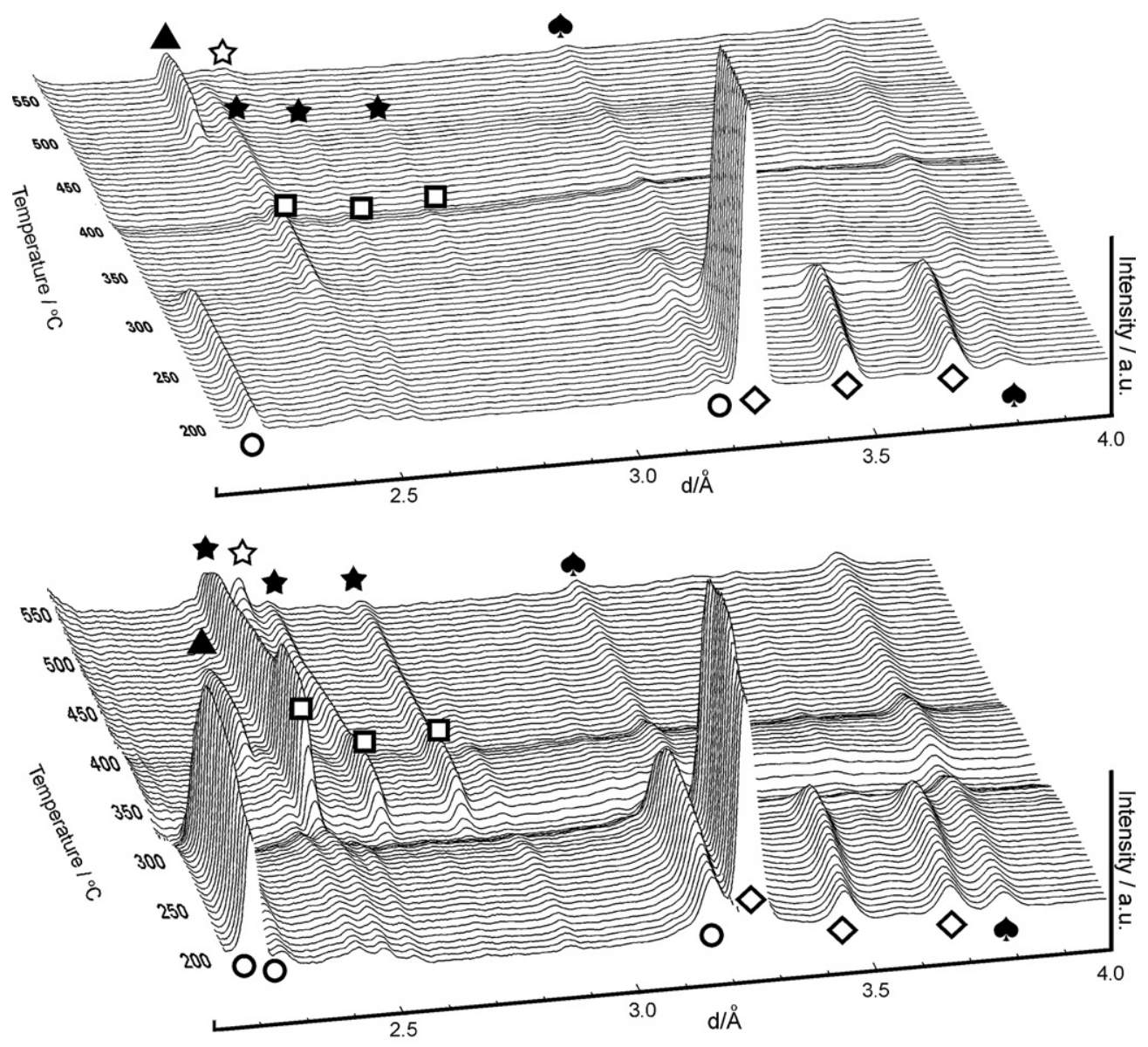

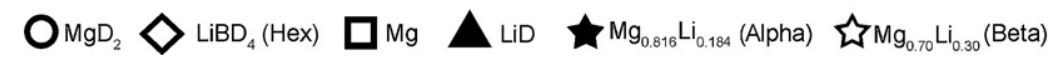

Stainless Steel

Fig. 4. In situ ND patterns for the decomposition of 2:1 (top) and 0.3:1 (bottom) $\mathrm{LiBD}_{4}-\mathrm{MgD}_{2}$ samples heated-up in a stainless steel vessel under a dynamic vacuum.

decrease in the second dehydrogenation peak for the $\mathrm{LiBH}_{4}-\mathrm{MgH}_{2}$ samples from 435 to $390^{\circ} \mathrm{C}$. It has been shown that $\mathrm{Mg}$ catalyses the decomposition of $\mathrm{LiBH}_{4}[4,7]$, but given that the dehydrogenation peak for the $\mathrm{MgH}_{2}$-rich mixtures is below the theoretical $T(1 \mathrm{bar})$ for $\mathrm{LiBH}_{4}$, it is unclear whether this is just a kinetic effect or if the $\mathrm{LiBH}_{4}$ has been thermodynamically destabilised by the presence of magnesium-containing phases. If the latter then one would expect to see a change in the decomposition pathway between the stoichiometric 2:1 and the more $\mathrm{MgH}_{2}$-rich compositions. To investigate this, in situ ND experiments were carried out on the $2: 1$ and 0.3:1 molar ratios.

For the decomposition under a deuterium atmosphere of the 2:1 sample, the $\mathrm{MgD}_{2}$ first decomposed at $335^{\circ} \mathrm{C}$ forming $\mathrm{Mg}$. The amorphous hump at $3.4 \AA$, was from the molten $\mathrm{LiBD}_{4}$ which did not change significantly during the decomposition of the $\mathrm{MgD}_{2}$, but did start decreasing in intensity at $440^{\circ} \mathrm{C}$, indicating the decomposition of the $\mathrm{LiBD}_{4}$ phase. However, $\mathrm{LiD}$ and $\mathrm{MgB}_{2}$ did not appear until $520^{\circ} \mathrm{C}$, which was towards the end of the loss of the amorphous hump. This is a similar mechanism to that identified by Bosenberg et al. [9], but the greater sensitivity for neutrons to light elements has more clearly identified the appearance of the end products. The overall reaction was:

$2 \mathrm{LiBD}_{4}+\mathrm{MgD}_{2} \rightarrow 2 \mathrm{LiD}+\mathrm{MgB}_{2}+4 \mathrm{D}_{2}$

(equivalent to $11.5 \mathrm{wt} . \% \mathrm{H}_{2}$ )

For the $\mathrm{LiBD}_{4}-\mathrm{MgD}_{2}$ 0.3:1 sample, a similar decomposition path was followed, except that the formation of $\mathrm{LiD}$ and $\mathrm{MgD}_{2}$ occurred slightly earlier at $475^{\circ} \mathrm{C}$, before the complete loss of the amorphous hump. After decomposition there was still Mg present as this phase was in excess, resulting in the overall reaction given in Eq. (8).

$0.3 \mathrm{LiBD}_{4}+\mathrm{MgD}_{2} \rightarrow 0.3 \mathrm{LiD}+0.15 \mathrm{MgB} 2+0.85 \mathrm{Mg}+1.45 \mathrm{D}_{2}$

(equivalent to $8.9 \mathrm{wt} . \% \mathrm{H}_{2}$ )

For the decompositions under vacuum, the decomposition of the $\mathrm{MgD}_{2}$ occurred for both samples at a similar temperature to

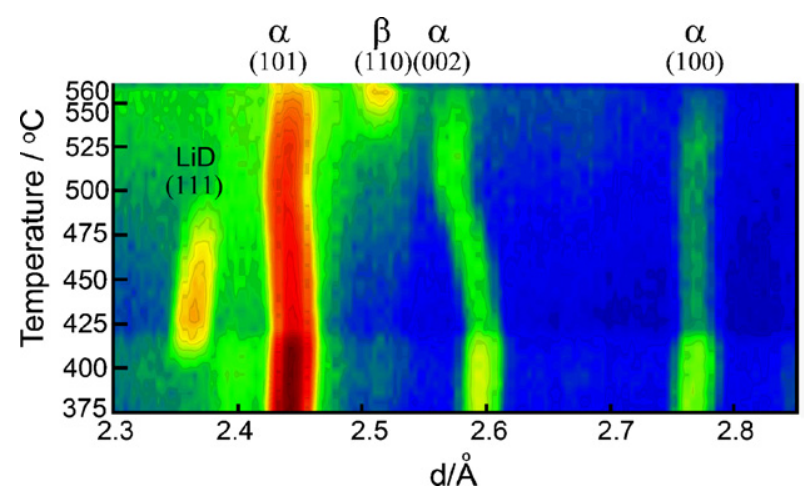

Fig. 5. In situ ND data for the decomposition under a dynamic vacuum of the $0.3: 1$ $\mathrm{LiBD}_{4}-\mathrm{MgD}_{2}$ sample (from the same experiment given in Fig. 4), showing the changing $d$-spacing during the formation of the $\mathrm{Mg}_{x} \mathrm{Li}_{y}$ alloys. 


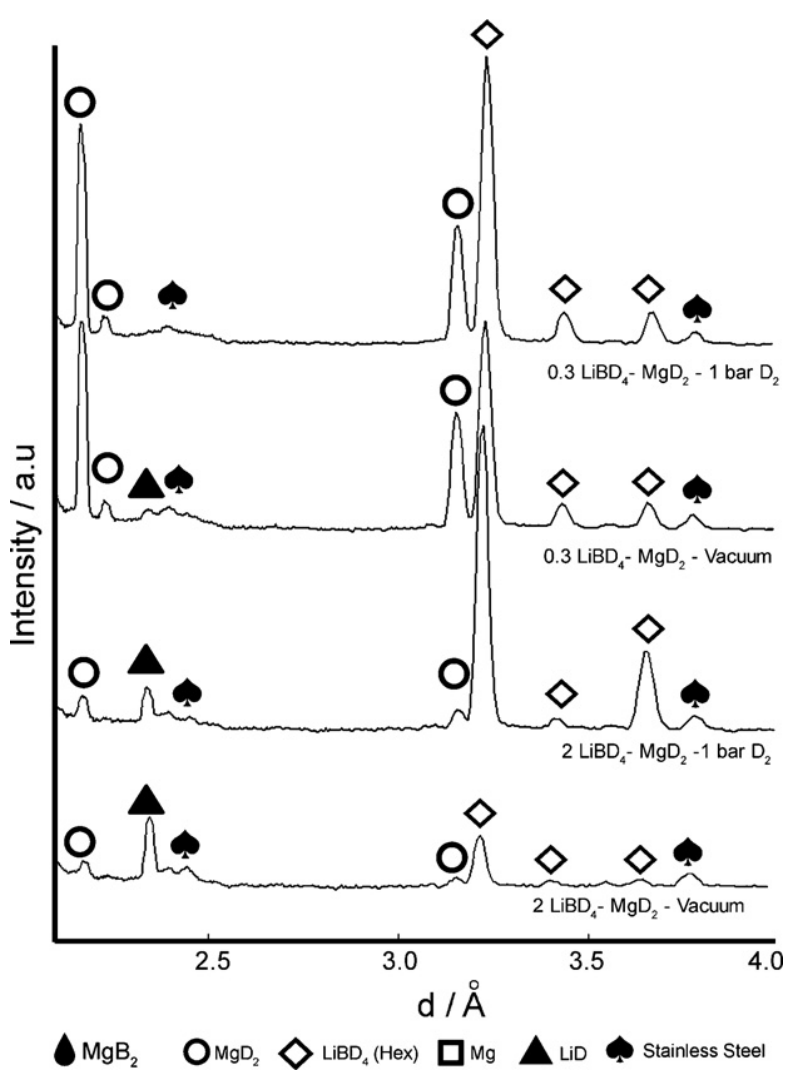

Fig. 6. ND patterns for redeuterided $0.3: 1$ and 2:1 $\mathrm{LiBD}_{4}-\mathrm{MgD}_{2}$ samples having been decomposed under either an initial pressure of 1 bar $D_{2}$ or under a dynamic vacuum (i.e. the decomposition products from the experiments shown in Figs. 4 and 5). Deuteriding conditions were $4 \mathrm{~h}$ at $400^{\circ} \mathrm{C}$ under 100 bar of $D_{2}$. Samples were cooled to $220^{\circ} \mathrm{C}$ before collecting the data.

the decompositions under a $\mathrm{D}_{2}$ pressure. For the $2: 1$ sample, the loss of the molten $\mathrm{LiBD}_{4}$ phase started at $440{ }^{\circ} \mathrm{C}$ (similar to the decompositions under $\mathrm{D}_{2}$ ) and a LiD phase started to form towards the end of the loss of the amorphous hump at $490^{\circ} \mathrm{C}$. Concomitant with the formation of LiD there was a shift in the $d$-spacing for the Mg phase as LiD was destabilised by the $\mathrm{Mg}$ forming $\mathrm{D}_{2}$ and enabling $\mathrm{Li}$ to diffuse into $\mathrm{Mg}$ forming the $\alpha-\mathrm{Li}_{x} \mathrm{Mg}_{y}$ alloy. This is the first reported identification of the formation of this alloy from a $\mathrm{LiBD}_{4}-\mathrm{MgD}_{2}$ 2:1 sample (or its hydrogen isotope equivalent). These alloys have been shown to be decomposition products for the $0.3: 1$ system $[4,7]$ and as the alloy forms from the destabilisation of LiD by Mg one would predict similar reactions to occur for the 2:1 system, although the alloy was not identified by Vajo et al. [3]. The $\alpha$-alloy has a Li solubility limit of 18.4 at.\% and further Li dissolution leads to the formation of the $\beta$-alloy, $\mathrm{Li}_{0.30} \mathrm{Mg}_{0.70}[7,13]$ and a weak reflection from this phase was identified on powder diffraction patterns towards the end of the experiment, with a corresponding loss of the $\alpha$-alloy. No boron-containing phase was identified and this was assumed to have been in a highly dispersed elemental form, the overall decomposition reaction is given in Eq. (9). The $\beta$-alloy has the potential to destabilise the remaining LiD, but it is not currently known whether the reaction continues, forming higher Li content $\beta$-alloy (the $\beta$-alloy has a Li solubility range from 30 to 100 at.\%).

$$
2 \mathrm{LiBD}_{4}+\mathrm{MgD}_{2} \rightarrow 1.57 \mathrm{LiD}+1.43 \mathrm{Li}_{0.30} \mathrm{Mg}_{0.70}+2 \mathrm{~B}+4.21 \mathrm{D}_{2}
$$

(equivalent to $12.1 \mathrm{wt} . \% \mathrm{H}_{2}$ )

The 0.3:1 sample decomposed under vacuum in a similar manner up to $400^{\circ} \mathrm{C}$. However, the molten $\mathrm{LiBD}_{4}$ amorphous hump in the ND data started to decrease in intensity slightly earlier at $400^{\circ} \mathrm{C}\left(40^{\circ} \mathrm{C}\right.$ lower than all the other samples $)$ and most significantly LiD started forming at $400^{\circ} \mathrm{C}$. This is a clear difference with the other decompositions where there was an induction period between the initial loss of the molten $\mathrm{LiBD}_{4}$ phase and formation of the decomposition product LiD. It should be noted that the induction time between these two events was shorter for the $0.3: 1$ sample decomposed under a $\mathrm{D}_{2}$ atmosphere compared with the $2: 1$ sample, indicating that the more magnesium-rich samples decomposed the borohydride more readily under both conditions. The induction period found for the 2:1 samples suggests that the $\mathrm{LiBD}_{4}$ formed an amorphous intermediate phase before decomposing to LiD. It has been proposed that $\mathrm{LiBH}_{4}$ decomposes forming other borohydride ions such as $\mathrm{LiBH}$ [14] and $\mathrm{Li}_{2} \mathrm{~B}_{12} \mathrm{H}_{12}$ [15] (although the latter should also produce $\mathrm{LiH}$ too). No intermediate appeared to be formed for the decomposition of the $0.3: 1$ sample under vacuum as LiD was produced at the same time as the $\mathrm{LiBD}_{4}$ phase was lost. One might expect intermediate phases to be more stable under a deuterium pressure explaining the difference between the decompositions under vacuum and under a deuterium atmosphere. However, this does not explain why an induction period was also observed for the decomposition of the 2:1 sample under vacuum. The excess of magnesium may help catalyse the decomposition of the $\mathrm{LiBD}_{4}$, but it is clear that for this composition the $\mathrm{LiBD}_{4}$ decomposed more readily (at a temperature $40^{\circ} \mathrm{C}$ lower) and decomposed directly to LiD.

The LiD that formed during the decomposition under vacuum of the $0.3: 1$ sample was destabilised by the presence of $\mathrm{Mg}$, resulting in the formation of $\mathrm{Li}_{x} \mathrm{Mg}_{y}$ alloys, a similar reaction to that found for the 2:1 sample. However, for the $0.3: 1$ sample all the LiD reacted resulting in the formation of both the $\alpha$-and $\beta$-alloys, which agrees with earlier results $[4,7]$. The Li content was 23 at.\% (with respect to $\mathrm{Mg}$ ) which falls within a two phase region of the $\mathrm{Li}-\mathrm{Mg}$ phase diagram [13], explaining why the there are two alloys present in the end products. The overall reaction was:

$$
\begin{array}{cc}
0.30 \mathrm{LiBD}_{4}+\mathrm{MgD}_{2} & \rightarrow 0.78 \mathrm{Li}_{0.184} \mathrm{Mg}_{0.816}+0.52 \mathrm{Li}_{0.30} \mathrm{Mg}_{0.70} \\
+0.3 \mathrm{~B}+1.60 \mathrm{D}_{2} & \text { (equivalent to } 9.8 \text { wt.\% } \mathrm{H}_{2} \text { ) }
\end{array}
$$

To investigate the reversibility of all the reactions, deuteriding was attempted at $400^{\circ} \mathrm{C}$, under 100 bar $\mathrm{D}_{2}$ pressure for $4 \mathrm{~h}$. The ND patterns for all the samples after redeuteriding showed reversibility for all the samples with $\mathrm{LiBD}_{4}$ and $\mathrm{MgD}_{2}$ phases having reformed. This is in contrast to earlier reports that decomposition of the 2:1 system under vacuum could not be reversed. However, the result in Fig. 6 shows that this reaction was only partially reversed (5\%), but with a significant amount of LiD still present. The highest conversion ( $>95 \%$ ) was found for the 0.3:1 sample decomposed under $D_{2}$. A higher reversibility in general was found for the $0.3: 1$ samples (>95\% and $70 \%$ cf. $40 \%$ and only $5 \%$ for the $2: 1$ samples) showing the importance that stoichiometry of the mixtures play in the cyclability of such destabilised systems. These are encouraging results even though samples had some unreacted LiD left, as no catalyst was used for these samples and hence these are not optimised systems. It has been shown that compounds such as titanium isopropoxide and vanadium(III) chloride are very effective catalysts for the 2:1 system [9].

This detailed investigation of the decomposition reactions of $\mathrm{LiBD}_{4}-\mathrm{MgD}_{2}$ has found that the decompositions under $\mathrm{D}_{2}$ appear to follow similar destabilised reactions regardless of the stoichiometry of the multicomponent system, forming $\mathrm{LiD}, \mathrm{MgB}_{2}$ and $\mathrm{Mg}$, the latter only when there was an excess of $\mathrm{MgD}_{2}$ in the as prepared materials. Intriguingly the $\mathrm{LiBD}_{4}$ liquid phase was lost prior to the formation of the end products and spectroscopic work is required to investigate what intermediates are being formed. For the decompositions under vacuum, $\mathrm{Mg}$ seems to act as a catalyst for the decomposition of the $\mathrm{LiBD}_{4}$, because there is no evidence 
for an end product from a destabilisation reaction (i.e. neither $\mathrm{MgB}_{2}$ nor $\mathrm{Mg}_{x} \mathrm{Li}_{y}$ were formed directly on decomposition of $\mathrm{LiBD}_{4}$ ). For the $0.3: 1$ mixture the formation of LiD was much more rapid, it actually appeared that no intermediate phase was formed during the decomposition. The presence of Mg destabilised the LiD and resulted in the formation of first the $\alpha$-alloy and subsequently the $\beta$-alloy. However, although the $\alpha$-alloy was a destabilisation agent the $\beta$-alloy appeared not to be, presumably because the $\beta$ alloy (which is based on the BCC crystal structure of $\mathrm{Li}$ ) is too thermodynamically similar to Li, therefore providing little if any thermodynamic destabilisation. This gives a maximum Li content for the alloy of 0.3 at.\% resulting in an optimum ratio for the LiD destabilisation reaction of $0.43: 1 \mathrm{LiBD}_{4}-\mathrm{MgD}_{2}$ (reaction equation (11)), which has an equivalent hydrogen storage capacity of 10.51 wt.\%.

$0.43 \mathrm{LiBD}_{4}+\mathrm{MgD}_{2} \rightarrow 1.43 \mathrm{Li}_{0.30} \mathrm{Mg}_{0.70}+0.43 \mathrm{~B}+1.86 \mathrm{D}_{2}$

\section{Conclusions}

It can be concluded that similar overall decomposition reactions proceed regardless of the stoichiometry of the starting materials, but the stoichiometry does affect the ratio of the end products depending on whether one component is in excess or not. The decomposition environment does have a big effect on the decomposition pathway. Mg-Li alloys were formed for the 2:1 mixture when decomposed under vacuum, but the destabilisation of the LiD phase by the Mg-containing phase appeared to proceed no further after the formation of the $\beta$-alloy (i.e. at a Li content of 0.3 at.\%). All the decompositions showed some reversibility, proving that a $\mathrm{MgB}_{2}$ decomposition product is not required for a reversible system. The 0.3:1 samples had higher conversions than the $2: 1$ systems for the conditions investigated.

\section{Acknowledgements}

The authors would like to thank the UK Engineering and Physical Science Research Council for funding through UKSHEC under the Supergen programme and to the ILL for access and support in undertaking experiment 5-25-145, in particular for the help and guidance from Drs. Thomas Hansen and Bachir Ouladdiaf.

\section{References}

[1] J.J. Reilly, R.H. Wiswall, Inorg. Chem. 7 (1968) 2254-2256.

[2] J.J. Vajo, F. Mertens, C.C. Ahn, R.C. Bowman, B. Fultz, J. Phys. Chem. B 108 (2004) 13977-13983.

[3] J.J. Vajo, S.L. Skeith, F. Mertens, J. Phys. Chem. B, Lett. 109 (2005) 3719-3722.

[4] T.E. Price, D.M. Grant, X.B. Yu, I. Telepeni, G.S. Walker, J. Alloys Compd. 472 (2009) 559-564.

[5] A. Züttel, P. Wenger, S. Rentsch, P. Sudan, P. Mauron, C. Emmenegger, J. Power Sources 118 (2003) 1-7.

[6] (a) D.R. Lide (Ed.), CRC Handbook of Chemistry and Physics, 83rd ed., CRC press London, 2002:

(b) M.W. Chase (Ed.), NIST-JANAF Thermochemical Tables, 4th ed., American Institute of Physics, New York, 1998.

[7] X.B. Yu, D.M. Grant, G.S. Walker, Chem. Commun. 37 (2006) 3906-3908.

[8] G. Barkhordarian, T. Klassen, M. Dornheim, R. Bormann, J. Alloys Compd. 440 (2007) L18-L21.

[9] Y. Bosenberg, S. Doppiu, L. Mosegaard, G. Barhordarian, N. Eigen, A. Borgschulte, T.R. Jensen, Y. Cerenius, O. Gutfleisch, T. Klassen, M. Dornheim, R. Bormann, Acta Mater. 55 (2007) 3951-3958.

[10] F.E. Pinkerton, M.S. Meyer, G.P. Meisner, M.P. Balogh, J.J. Vajo, J. Phys. Chem. C 111 (2007) 12881-12885.

[11] J.J. Vajo, G.L. Olson, Scr. Mater. 56 (2007) 829-834.

[12] T.C. Hansen, P.F. Henry, H.E. Fischer, J. Torregrossa, P. Convert, Meas. Sci. Technol. 19 (2008) 034001.

[13] M. Hansen (Ed.), Constitution of Binary Alloys, 2nd ed., McGraw-Hill, New York 1958, pp. 897-898.

[14] J.K. Kang, S.Y. Kim, Y.S. Han, R.P. Muller, W.A. Goddard III, Appl. Phys. Lett. 87 (2005) 111904

[15] N. Ohba, K. Miwa, M. Aoki, T. Noritake, S. Towata, Y. Nakamori, S. Orimo, Phys. Rev. B 74 (2006) 075110 